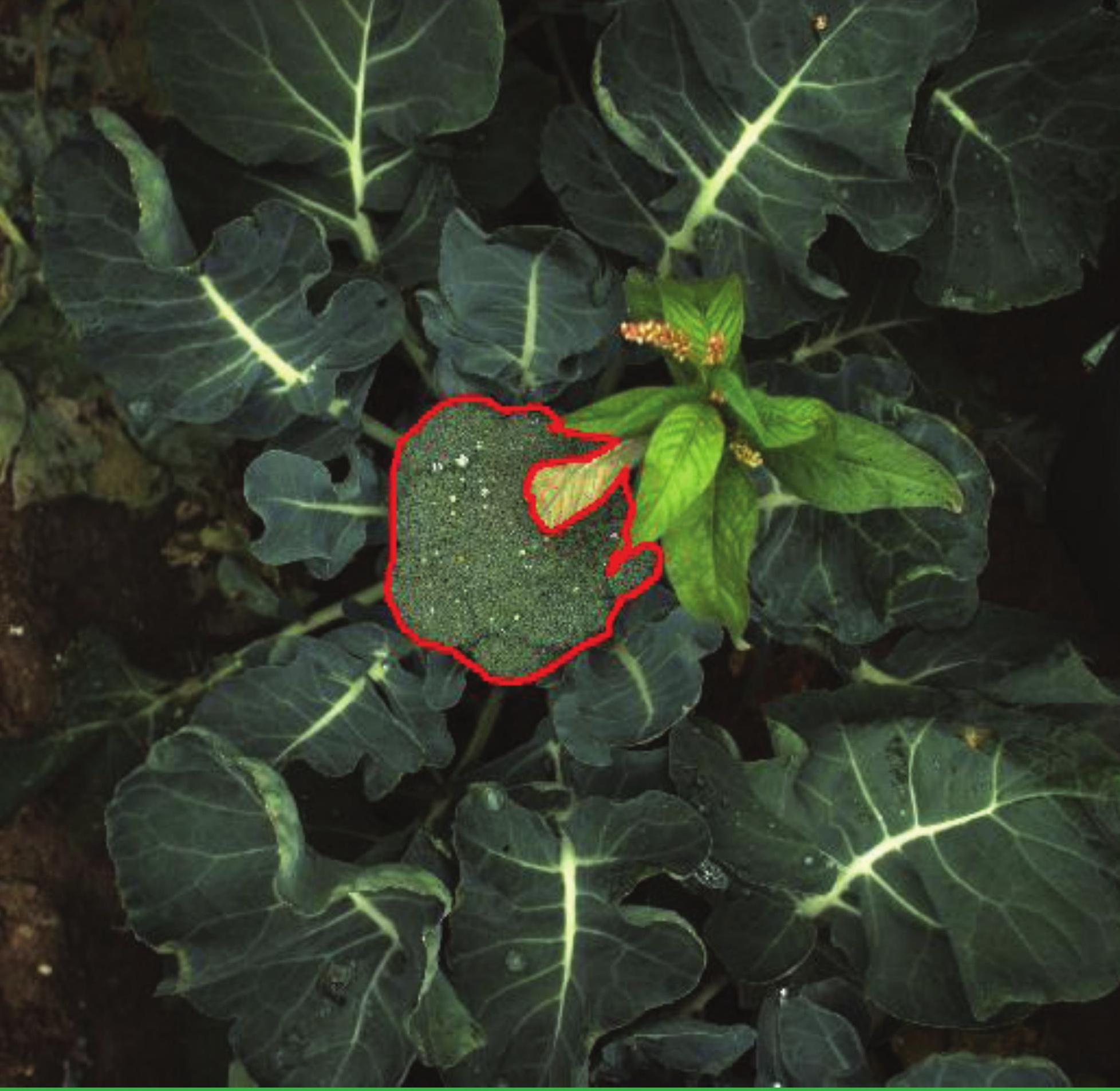

Ontwikkeling en validatie van computer vision technologie ten behoeve van een broccoli oogstrobot 



\section{Ontwikkeling en validatie van computer vision technologie ten behoeve van een broccoli oogstrobot}

Pieter M. Blok ${ }^{1}$, Antonius P.M. Tielen ${ }^{1}$

1 Wageningen University \& Research

Dit onderzoek is in opdracht van Agritronics BV uitgevoerd door de Stichting Wageningen Research (WR),

Business unit Agrosysteemkunde, in het kader van beleidsondersteunend onderzoeksthema Precisietechnologie

Tuinbouw (projectnummer BO-25.06-003-003.00).

WR is een onderdeel van Wageningen University \& Research, samenwerkingsverband tussen Wageningen University en de Stichting Wageningen Research.

Wageningen, mei 2018

Rapport WPR-799 
Pieter M. Blok, Antonius P.M. Tielen, 2018. Ontwikkeling en validatie van computer vision technologie ten behoeve van een broccoli oogstrobot. Wageningen Research, Rapport WPR-799. 20 blz.; 7 fig.; 4 tab.; 12 ref.

Dit rapport is gratis te downloaden op https://doi.org/10.18174/448976

\section{Referaat}

De selectieve en handmatige oogst van broccoli is arbeidsintensief en omvat ongeveer $35 \%$ van de totale productiekosten. Dit onderzoek is uitgevoerd om te bepalen of computer vision kan worden gebruikt om broccoli kronen te detecteren, als eerste stap in de ontwikkeling van een autonome selectieve broccoli oogstrobot. Een op textuur en kleur gebaseerde beeld detectie is gebruikt om de broccoli kronen van de achtergrond te scheiden. De computer vision is gevalideerd met een ground truth dataset van 200 afbeeldingen. In deze beelden zijn 228 werkelijke broccoli kronen van verschillende groottes aangewezen door twee menselijke experts gebruikmakend van het GrabCutalgoritme. De broccoli detectie van de computer vision is op twee verschillende manieren beoordeeld. De eerste was een pixel-gebaseerde overlap tussen de computer vision en de werkelijke broccoli objecten, wat resulteerde in een gemiddelde overlap van $93.8 \%$. De tweede waarde was op basis van de detectie van de individuele broccoli kronen. Deze toonde een precisie van $99.5 \%$, met een slechts één onterecht aangemerkte broccoli. De specificiteit was $97.9 \%$, de negative predictive value was $69.7 \%$ en de gemiddelde nauwkeurigheid was $92.4 \%$. In het totaal zijn 208 broccoli kronen gedetecteerd door de computer vision, wat wijst op een sensitiviteit van $91.2 \%$. De gemiddelde grootte van de gemiste kronen was kleiner dan de gemiddelde grootte van de gedetecteerde kronen. Indien de broccoli kronen slechter zichtbaar zijn of overschaduwd worden door omringende bladeren is het mogelijk dat de computer vision misclassificaties levert.

Trefwoorden: Landbouw, Camera's, Computer vision, Beeldverwerking, Intelligente machines

Dit project is mede tot stand gekomen door de bijdrage van de Topsector Tuinbouw \& Uitgangsmaterialen en het Ministerie van Landbouw, Natuur en Voedselkwaliteit (LNV).

(C) 2018 Wageningen, Stichting Wageningen Research, Wageningen Plant Research, Business unit Agrosysteemkunde, Postbus 16, 6700 AA Wageningen; T 03174807 00; www.wur.nl/plant-research

KvK: 09098104 te Arnhem

VAT NL no. 8113.83.696.B07

Stichting Wageningen Research. Alle rechten voorbehouden. Niets uit deze uitgave mag worden verveelvoudigd, opgeslagen in een geautomatiseerd gegevensbestand, of openbaar gemaakt, in enige vorm of op enige wijze, hetzij elektronisch, mechanisch, door fotokopieën, opnamen of enige andere manier zonder voorafgaande schriftelijke toestemming van Stichting Wageningen Research.

Stichting Wageningen Research is niet aansprakelijk voor eventuele schadelijke gevolgen die kunnen ontstaan bij gebruik van gegevens uit deze uitgave.

Rapport WPR-799

Foto omslag: Automatische detectie van broccoli door middel van computer vision 


\section{Inhoud}

$\begin{array}{ll}\text { Woord vooraf } & 5\end{array}$

$\begin{array}{lll}1 & \text { Inleiding } & 7\end{array}$

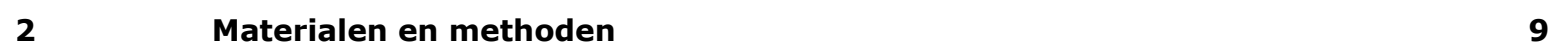

$2.1 \quad$ Beeld acquisitie module $\quad 9$

2.2 Veldexperimenten en beeldopnames 9

$\begin{array}{ll}2.3 \text { Ground truth bepaling } & 10\end{array}$

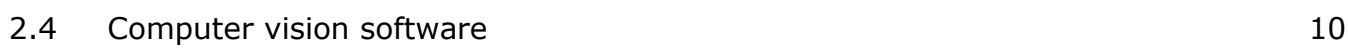

2.5 Evaluatie 12

$\begin{array}{llr}3 & \text { Resultaten } & 13\end{array}$

$3.1 \quad$ Broccoli pixel segmentatie $\quad 13$

3.2 Object detectie van individuele broccoli kronen $\quad 14$

$\begin{array}{lll}3.3 & \text { Beeld analyse tijd } & 15\end{array}$

$\begin{array}{llr}4 & \text { Discussie } & 16\end{array}$

$\begin{array}{llr}5 & \text { Conclusie } & 17\end{array}$

$\begin{array}{lr}\text { Literatuur } & 18\end{array}$ 



\section{Woord vooraf}

Wij danken Agritronics VOF, Agritronics BV en de Firma Goodijk voor hun toewijding en prettige samenwerking tijdens dit project. 


\section{$1 \quad$ Inleiding}

Broccoli (Brassica oleracea convar. botrytis var. italica), geteeld voor de vers markt, is een hoogwaardige groente. Naar schatting wordt er jaarlijks 120.000 ha broccoli wereldwijd geteeld (Grubben and Denton, 2004). Doordat de broccoli's buiten op de akker worden geteeld, is er een grote variatie tussen de planten en de daarop groeiende kronen (het product). Desondanks eist de levensmiddelenbranche dat er een uniform product wordt geleverd, overeenkomstig aan United Nations Economic Commission for Europe (UNECE) Standard FFV-48. In deze is vastgelegd dat de kroon diameter van een verse broccoli tenminste $6 \mathrm{~cm}$ breed moet zijn en dat er een verhouding van 2:1 is van kroon tot kroonsteel (UNECE Standard FFV-48, 2010). Daarnaast moet de kroon vrij zijn van blaadjes en de bloemknoppen volledig gesloten zijn.

In de huidige praktijk wordt broccoli voor de verse markt handmatig geoogst. Het is een selectieve wijze van oogsten aangezien de oogsters elke broccoli visueel moeten beoordelen op grootte en rijpheid. Omgekeerd betekend dit dat deze wijze van oogsten ervaren oogsters vraagt (Ramirez, 2006). Door de wijze van oogsten wordt van de oogsters verwacht dat ze gedurende een aantal dagen of weken elke gewasrij opnieuw beoordelen op grootte en rijpheid zodat alleen verkoopbare broccoli's worden geoogst. Dit stelt hoge eisen aan de oogsters en geeft ook een hoge fysieke belasting. Om één ha broccoli handmatig en selectief te oogsten is in Nederland naar schatting $100-150$ uur nodig, die een kostenpost van $€ 1900$ - $€ 2500$ per ha oplevert (Schreuder en Hendriks-Goossens, 2010). Berekeningen uit Californië (VS) schatten de oogstkosten tussen $\$ 2000$ - $\$ 2500$ per ha, wat overeenkomt met 35\% van de totale productie kosten (Surendra et al., 2012).

Er bestaan gemechaniseerde vormen van broccoli oogsten. De bestaande machines kunnen echter bij de oogst geen onderscheid maken in kroon grootte, waardoor alle kronen in één werkgang worden geoogst. Een aantal telers hebben problemen met deze wijze van oogsten, omdat hiermee slechts $50 \%$ van het geoogste product op de vers markt kan worden afgezet (Walton and Casada, 1988). Doordat kleinere broccoli's voortijdig worden geoogst en zodoende niet meer kunnen uitgroeien tot de gewenste grootte, betekend dat door deze oogsttechniek niet het volledige potentieel uit een broccoli perceel gehaald kan worden. Dit is de belangrijkste reden om een nieuwe oogsttechniek op te zetten, waarbij met behulp van een robot de broccoli's selectief kunnen worden geoogst. Het project wat hier voor was opgesteld had als doel om een prototype oogstmachine te ontwikkelen die broccoli kronen selectief en autonoom oogst, waarbij de geoogste broccoli voldoet aan de gestelde sortering en kwaliteit met een reductie van de benodigde arbeidskrachten. De robot zal alleen kronen oogsten die groter zijn dan een minimum grootte, waardoor de kleinere broccoli's blijven staan op het veld voor verdere groei. Deze kronen mogen niet beschadigd worden, door het passeren van de oogstmachine. Zo kan het perceel op meerdere momenten autonoom worden geoogst en kan een meer uniforme broccoli kwaliteit worden bereikt voor de teler.

De huidige robot bestaat uit één module voor de beeld opnames en één grijparm, beide opgebouwd op een werktuigendrager (Figuur 1). De beeld acquisitie module gebruikt een kleurcamera om opnames van het gewas te maken. De grijparm, bestaande uit een snij kop, snijdt de broccoli af en transporteert deze naar een afvoerband. Een belangrijke informatiebron voor de robot is de object herkenning door computer vision software, voor het detecteren van oogstbare broccoli kronen. De wetenschappelijke literatuur toont eerdere onderzoeken in dit werkveld. Zo is er onderzoek gedaan naar de automatische detectie van broccoli kronen, met kleur reflectie (Soule and Sides, 1988), multispectraal reflectie (Qui and Shearer, 1992) en patroon herkenning van blad nerven (Ramirez, 2006). Deze onderzoeken concludeerden dat het werken met licht reflectie geen goed resultaat gaf doordat het omgevingslicht in het veld te overheersend is. Het onderzoek naar de blad nerven toonde een marginaal onderscheidend vermogen door het verstorende patroon van de broccoli kroon.

Het doel van dit onderzoek was het ontwikkelen en testen van computer vision technologie (hard- en software) voor het herkennen van broccoli kronen in het veld. Met name de manier van beeld 
opnames en de software detectie op pixel-niveau van de broccoli kroon wordt beschreven. Dit rapport dient als basis om te komen naar een volledig autonome broccoli oogstrobot op basis van computer vision. De projectverantwoordelijkheid van Wageningen Research betrof de ontwikkeling van de computer vision technologie. De technologie van de grijparm wordt niet in detail beschreven in verband met intellectuele geheimhouding van onze projectpartner (Agritronics BV).

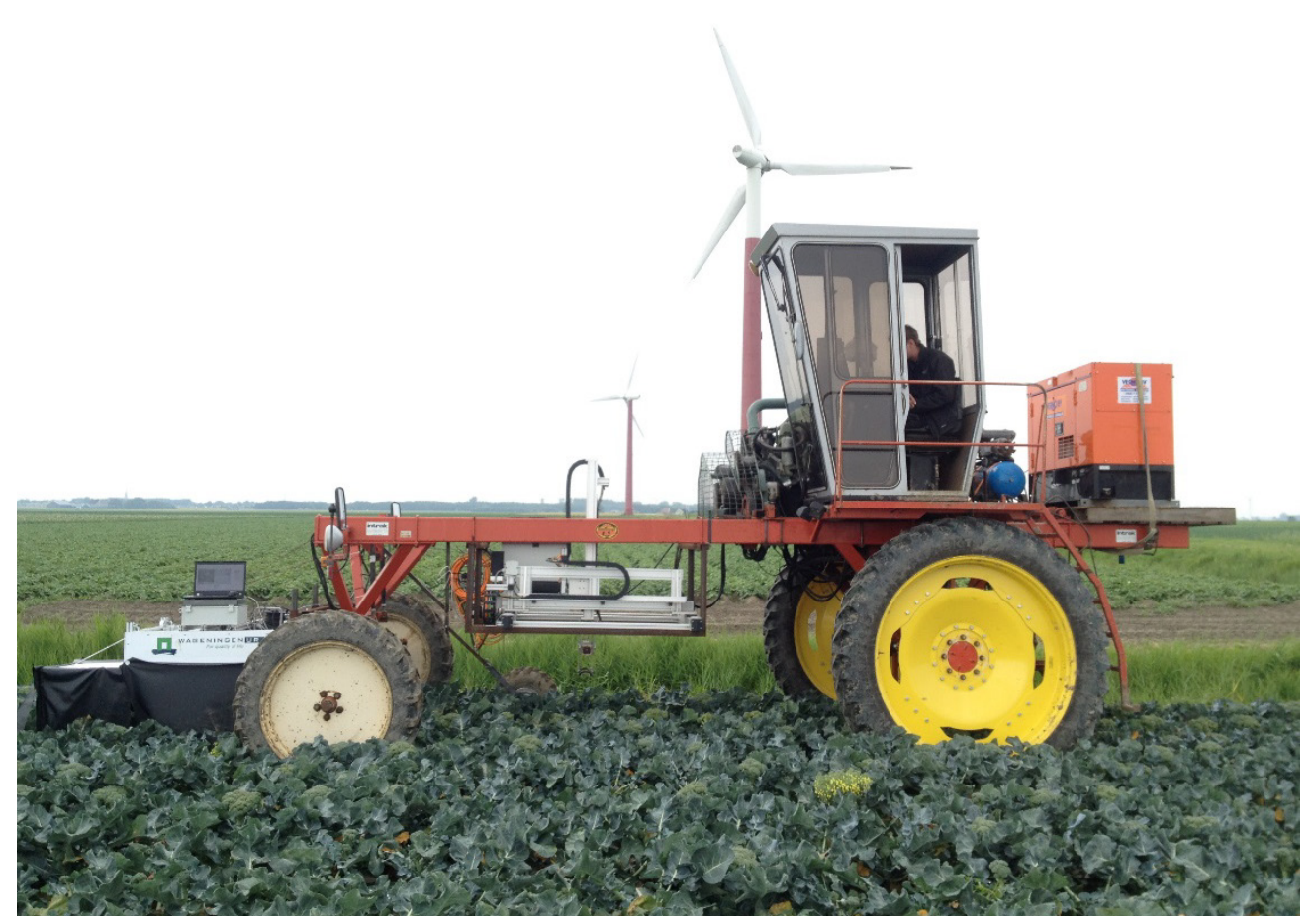

Figuur 1 Testplatform waarmee in het veld de experimenten zijn uitgevoerd. 


\section{$2 \quad$ Materialen en methoden}

\section{$2.1 \quad$ Beeld acquisitie module}

De module voor de beeld opnames was een vierkante box van 1,1-0,8-1,0 m (Ixbxh) uitgerust met een 5 megapixel kleuren camera, kunstlicht en een computer. Door toepassing van een zwart rubberen gordijn werd getracht de invloed van het omgevingslicht op de beeldopnames te minimaliseren. Het kunstlicht kwam uit 50 witte $(6000 \mathrm{~K})$ led strips van 80 centimeter lengte, die in een regelmatig patroon tegen het plafond waren gemonteerd. Elke led strip produceerde licht onder een hoek van $120^{\circ}$ wat een totale licht flux / opbrengst gaf van 13.500 lumen binnen in de box. Dit gaf een fel en diffuus licht patroon over de planten zonder verstoring van het omgevingslicht (Figuur 2). De opnames werden gemaakt met een 5 megapixel RGB camera (AVT Prosilica GC2450C met $2448 \times 2050$ pixels). Deze camera was zo gemonteerd dat het recht naar beneden keek op een hoogte van $50 \mathrm{~cm}$ van het broccoli gewas. De communicatie tussen de camera en de beeldverwerkingscomputer (Intel Core i7-2030QM processor, $2 \mathrm{GHz}$ clock speed) verliep via een ethernet verbinding. Elke $150 \mathrm{~mm}$ (+/- 1,3 mm) werd een hardware trigger gegenereerd afkomstig van een wiel encoder bevestigd aan het rechter voorwiel van de werktuigendrager. Door middel van deze trigger werd de camera opgedragen een foto te nemen. De opeenvolgende beelden hadden een gemiddelde overlap van $46 \%$.
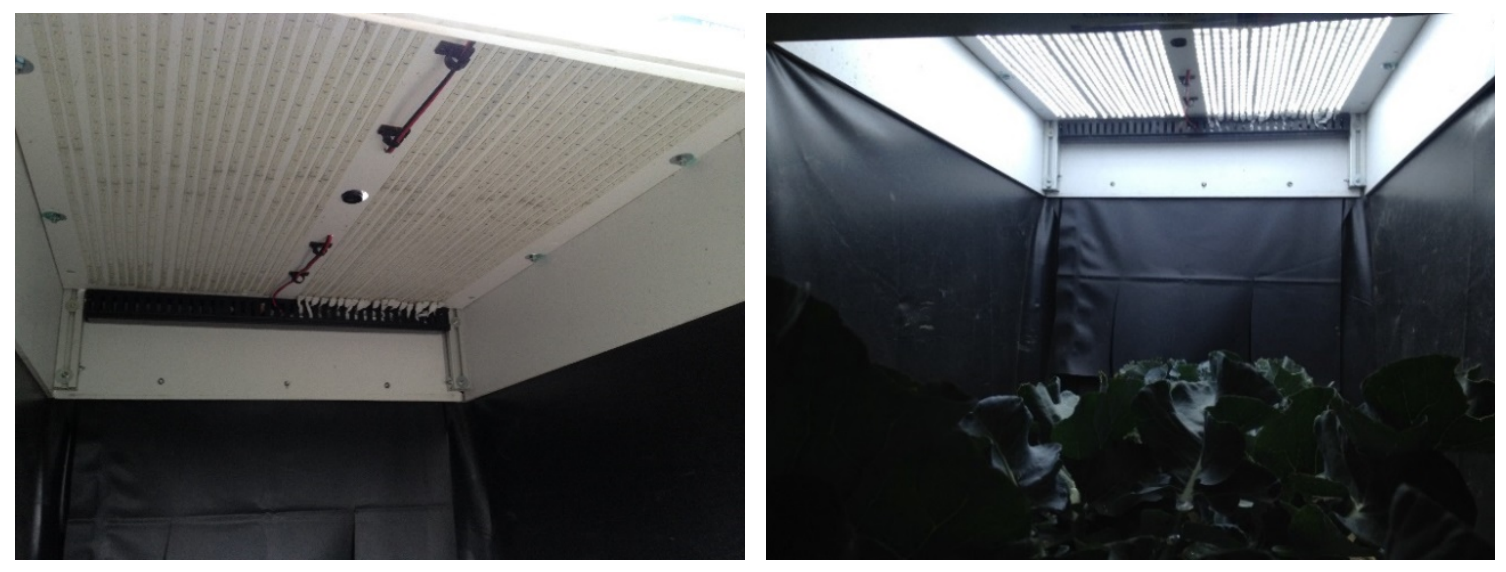

Figuur 2 Beeld acquisitie module met in het midden de ronde uitsnede voor de kleur camera.

\subsection{Veldexperimenten en beeldopnames}

In 2014, 2015, 2016 en 2017 zijn op vijftien verschillende momenten op verschillende percelen in Sexbierum (Friesland) in totaal 130.000 opnames van broccoli planten gemaakt. De broccoli werd geteeld op tien verschillende percelen en er werden 2 rassen geteeld: het zomergewas Ironman en het herfstgewas Steel (beide rassen zijn afkomstig van Seminis). Het gewas werd geteeld met een rijafstand van $75 \mathrm{~cm}$ en een plantafstand van $30 \mathrm{~cm}$. Uit de complete dataset zijn vijf willekeurige datasets gegenereerd (Tabel 1 ).

Tabel 1 Datasets gebruikt voor de beeld analyse.

\begin{tabular}{clccc} 
Code dataset & datum & Aantal opnames & Ras \\
D1 & $7-10-2014$ & 1655 & Steel \\
\hline D2 & $13-7-2015$ & 2352 & Ironman \\
\hline D3 & $15-7-2015$ & 1916 & Ironman \\
\hline D4 & $10-8-2016$ & 742 & Ironman \\
\hline D5 & $20-09-2017$ & 343 & Steel \\
\hline
\end{tabular}


De vijf datasets bestaan uit opnames van verschillende afmetingen van broccoli kronen, van verschillende plant lengtes en verschillende posities; maar ook opnames zonder broccoli, kale grond, verouderd blad en onkruiden.

\subsection{Ground truth bepaling}

Uit de dataset werden 200 beeld opnames willekeurig geselecteerd: 39 uit D1, 78 uit D2, 59 uit D3, 21 uit D4 en 3 uit D5. Alle broccoli kronen in de beelden werden gemarkeerd ongeacht hun grootte, aangezien er geen kroongrootte meting door de mens op deze 130.000 beelden was uitgevoerd. De bepaling van werkelijke broccoli kronen in het beeld, "ground truth" genaamd, werd uitgevoerd met behulp van het GrabCut algoritme (Rother et al., 2004). Daarna werd door een onafhankelijke menselijke expert de GrabCut segmentatie verfijnd op pixelniveau door een masker over de broccoli kroon te vormen (Figuur 3). Vervolgens werd het geannoteerde beeldresultaat door een tweede menselijke expert beoordeeld. Voor elke opname werd dusdanig de ground truth bepaling opgeslagen (Figuur 3).

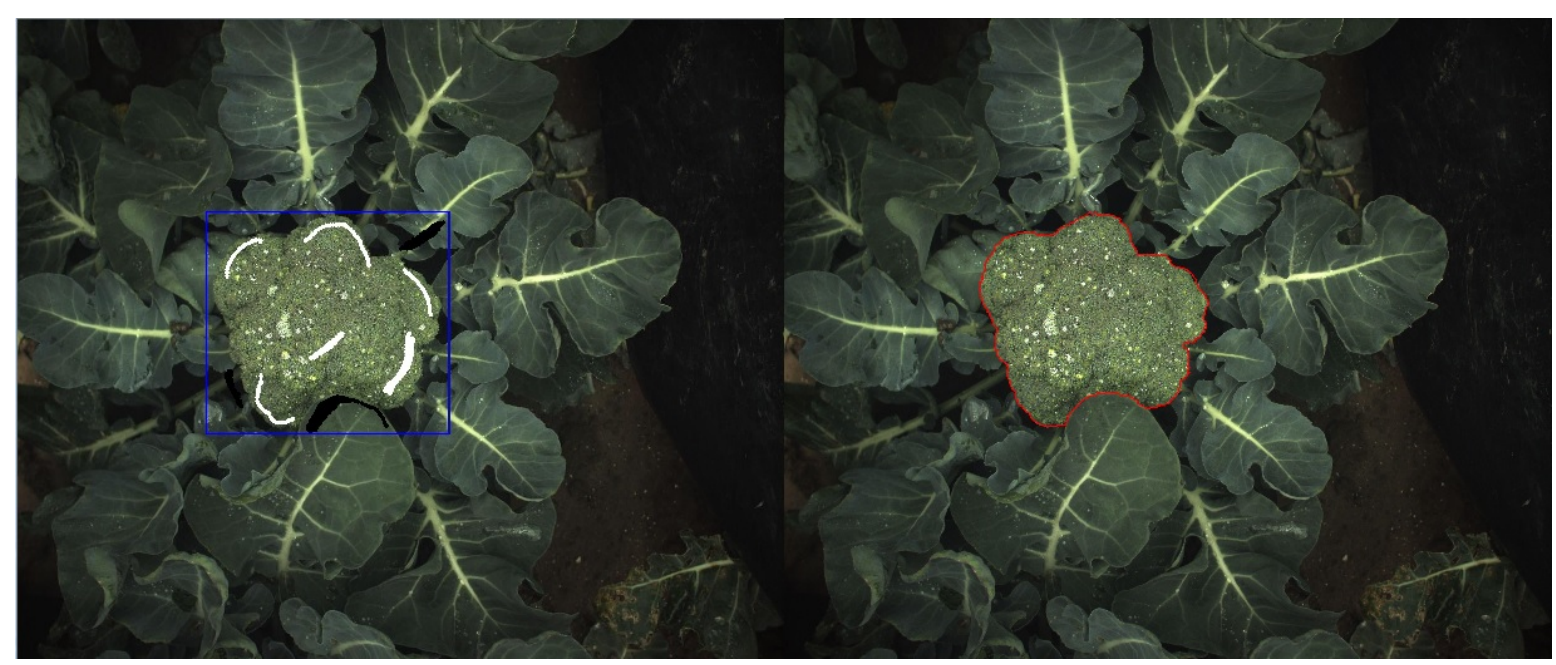

Figuur 3 Resultaten GrabCut analyse op een broccoli kroon. Het blauwe vierkant geeft de input aan en de afbakening van de broccoli kroon (witte lijnen) door de menselijke expert. De GrabCut output voor de ground truth classificatie is aangegeven door de rode omlijning in de rechtste figuur.

\subsection{Computer vision software}

De computer vision software is ontwikkeld met het softwareprogramma MVTec Halcon (v12). Het doel van de ontwikkelde software was om de broccoli kronen te detecteren in de beeldopname en te scheiden van de andere plant delen en ondergrond. Een belangrijk onderscheidend beeldkenmerk is de textuur van de broccoli. Doordat een broccoli kroon is opgebouwd uit minuscule bloemknoppen, is de textuur van de kroon verschillend ten opzichte van andere objecten, zoals bladeren, blad nerven en grond.

De eerste stap in de software was het vergroten van het contrast van het 24-bit kleurenbeeld. Zodoende werd het contrast tussen de kleine bloemknoppen vergroot (sub figuur 1 in Figuur 4). Deze procedure is uitgevoerd met een low-pass filter met een grootte van $7 \times 7$ pixels. Het resulterende grijswaarde beeld is vervolgens bewerkt met een E7*E7 Law's texture filter. Dit filter versterkt de lokale textuur in het beeld (sub figuur 2 in Figuur 4).

Daarna is een median filter van $60 \times 60$ pixels toegepast om de beeldruis weg te filteren. Aan elkaar grenzende beeldpixels werden geclusterd tot een regio (sub figuur 3 in Figuur 4). De pixel grootte van een regio is berekend en gefilterd met een minimale waarde van 25.000 pixels om ruis te verwijderen. 
Van de resterende regio's die gelden als mogelijk broccoli object, zijn de interne gaten opgevuld (sub figuur 4 in Figuur 4).

Vervolgens zijn er verschillende kleurtransformaties toegepast. Allereerst is het RGB kleurenbeeld omgezet naar het hue, saturation en intensity (HSI) kleurenspectrum. Een 5-pixel median filter is toegepast op het hue kanaal. Op elke aaneengesloten regio is een drempelwaarde toegepast om de groene objecten van de achtergrond te scheiden. Een drempelwaarde op het gele kanaal is uitgevoerd om vergeelde bladeren eruit te filteren. Daarnaast zijn andere verstorende objecten (zoals waterdruppels) eruit gefilterd met een drempelwaarde op de Intensity kanaal (sub figuur 5 in Figuur 4).

Op de resterende objecten is een selectie op basis van morfologische eigenschappen, zoals object grootte en vorm, toegepast wat het detectie resultaat geeft in sub figuur 6 van Figuur 4 .

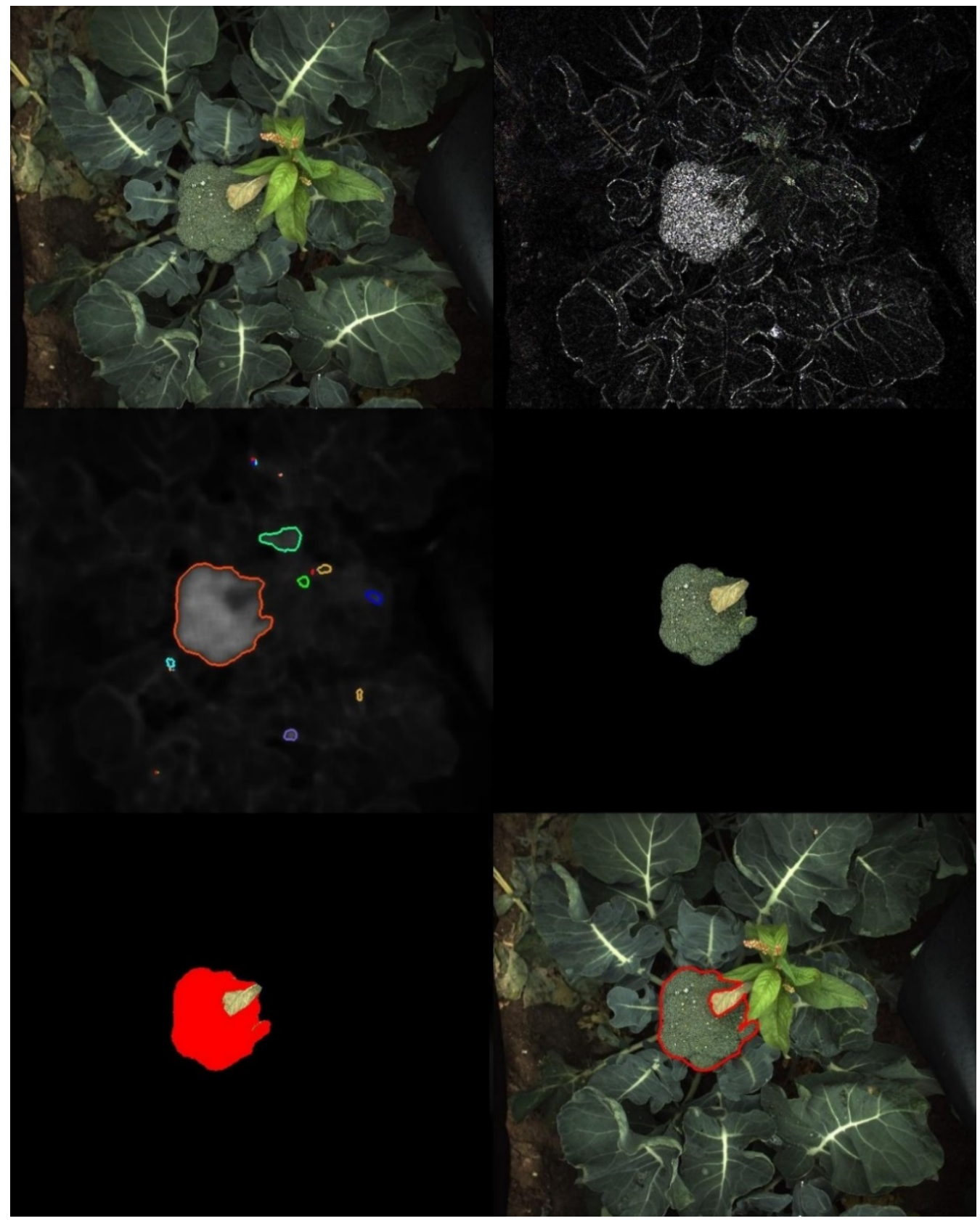

Figuur 4 Een subset van de computer vision stappen, startende bij het originele beeld (1), gevolgd door de E7XE7 texture Laws' energy filter (2) en een 60x60 pixels median filter (3). Vervolgens is er een selectie gedaan van de objecten op basis van oppervlak welke resulteert in mogelijke broccoli objecten (4). De volgende stap is het elimineren van de gele en hoge intensiteitsdelen van het kleurenbeeld (5), wat resulteert in de uiteindelijke beelddetectie aangegeven met de rode lijn (6). 


\section{$2.5 \quad$ Evaluatie}

De broccoli detectie van de computer vision is op twee verschillende manieren beoordeeld. De eerste betrof een pixel gebaseerde overlap per individueel beeld en de tweede een object gebaseerde vergelijking per broccoli.

De pixel segmentatie is geëvalueerd met de Dice Similarity Coefficient (DSC) (Dice,1946), welke een ratio weergeeft van de overlap tussen de computer vision $\left(P^{G T}\right)$ en de werkelijkheid $\left(P^{A R}\right)$. De DSC waarde ligt tussen 0 en 100 . 0 betekent geen spatiele overlap tussen de werkelijkheid en de computer vision en 100 betekent een complete pixel-match van $100 \%$.

$$
\operatorname{Dice}(\%)=\frac{2 *\left|P^{G T} \cap P^{A R}\right|}{\left|P^{G T}\right|+\left|P^{A R}\right|} * 100
$$

Omdat de dataset ook afbeeldingen bevatte zonder broccoli kroon, is een extra berekening per object uitgevoerd. De object gebaseerde broccoli detectie is geëvalueerd door middel van een confusion matrix, waarin de beslissing met computer vision vergeleken wordt met de werkelijkheid (ground truth). Wanneer het gesegmenteerde oppervlak meer dan 50\% van het ground-truth object besloeg, is deze segmentatie als een "True Positive" (TP) geclassificeerd. Wanner dit getal onder de 50\% was, is een "False Negative" (FN) gegenereerd. Een "True Negative" (TN) werd gegenereerd als er geen broccoli in het ground truth beeld was en er ook geen detectie door de computer vision. In het geval dat het gesegmenteerde beeld en de werkelijke achtergrond meer dan $50 \%$ overlapte werd een "False Positive" (FP) aangemerkt. De volgende performance indicatoren zijn met behulp van de bovengenoemde parameters berekend:

$$
\begin{gathered}
\text { sensitiviteit }(\%)=\frac{T P}{T P+F N} * 100 \\
\text { specificiteit }(\%)=\frac{T N}{T N+F P} * 100 \\
\text { precisie }(\%)=\frac{T P}{T P+F N} * 100 \\
\text { negative_predictive_value }(\%)=\frac{T N}{T N+F N} * 100 \\
\text { nauwkeurigheid }(\%)=\frac{T P+T N}{T P+T N+R P+F N} * 100
\end{gathered}
$$




\section{Resultaten}

\subsection{Broccoli pixel segmentatie}

In onderstaande Tabel 2, staat voor de 200 geanalyseerde beelden de gemiddelde Dice similarity coëfficiënt (DSC) per dataset en de totale dataset. Gemiddeld was de DSC 93,8\%. De standaard deviatie van de DSC bij het zomergewas (D2,D3,D4) is kleiner dan het herfstgewas (D1,D5), zie Figuur 5. In Figuur 6 is te zien dat het merendeel van de broccoli kronen van D1 en D5 kleiner waren. Een visuele inspectie van de beelden benadrukte dat bij D1 en D5 de kronen minder belicht waren doordat ze dieper in de plant zaten en zodoende meer overschaduwd waren door omringende bladeren. Ook was er duidelijk verband waarneembaar tussen de grootte van de kroon en het contrastniveau van de bloemknopjes. Het zomergewas bestond voornamelijk uit grote kronen met een hoog contrast tussen de bloemknopjes, terwijl bij het herfstgewas het tegenovergestelde bleek.

Tabel 2 Gemiddelde DSC en standaard deviatie voor de verschillende opnamedagen. Totale dataset geeft de gemiddelde DSC en standaarddeviatie van alle 200 opnames.

\begin{tabular}{lcc} 
Meetdag & Gemiddelde DSC $(\%)$ & Standaard deviatie \\
\hline D1 : 7-10-2014 & 83.8 & 33.0 \\
\hline D2 : $13-7-2015$ & 97.0 & 2.6 \\
\hline D3 : $15-7-2015$ & 96.1 & 3.4 \\
\hline D4 : $10-8-2016$ & 96.0 & 4.4 \\
\hline D5 : $20-09-2017$ & 75.9 & 15.7 \\
\hline Totale dataset & 93.8 & 15.8
\end{tabular}

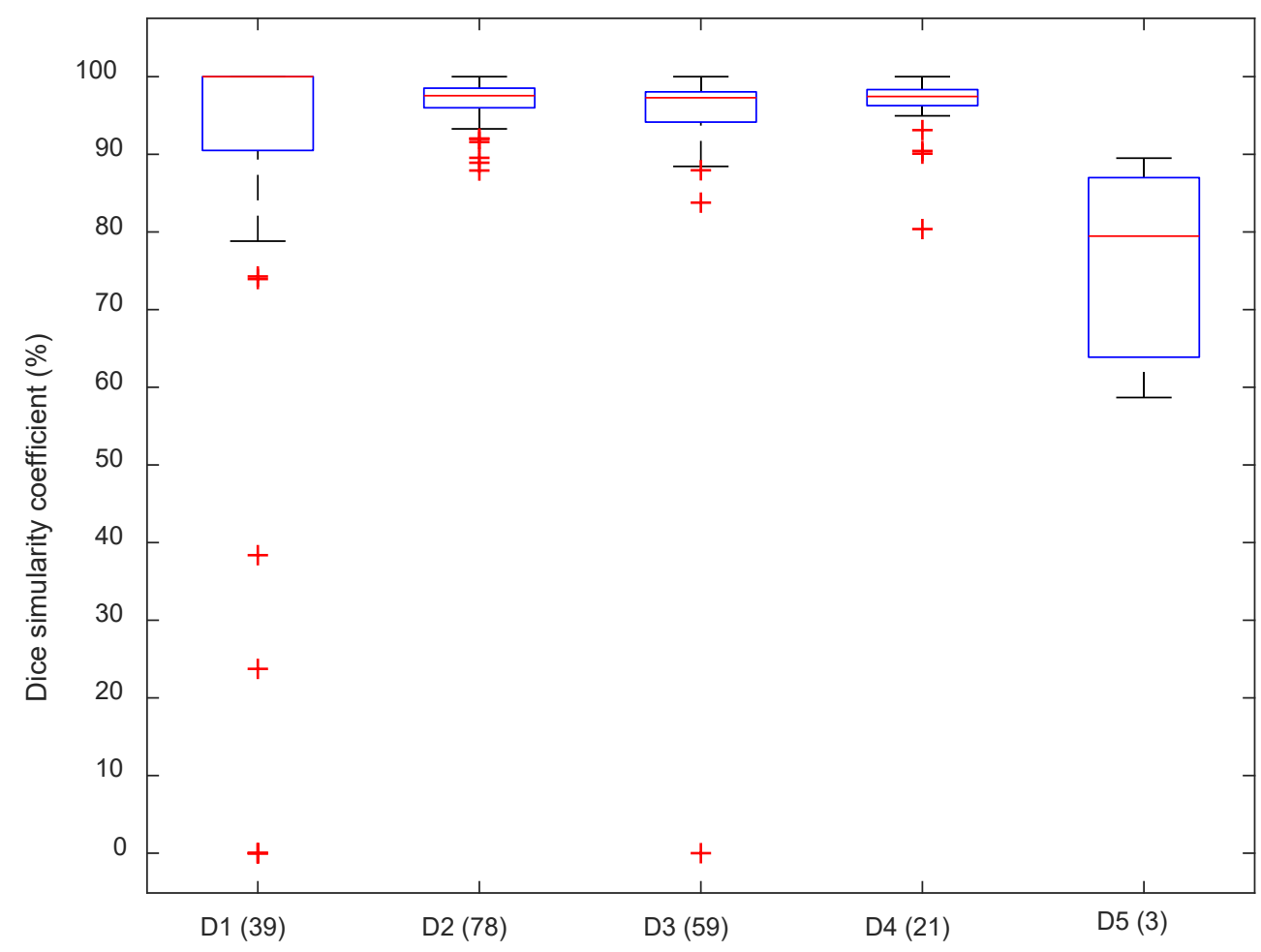

Figuur 5 Boxplot van de DSC van de verschillende meetdagen (D1-D5), met de mediaan (rode lijn), het eerste en derde kwartiel (blauwe rechthoek), het minium en maximum (zwarte lijn) en de uitschieters (rode kruizen). Tussen haakjes op de horizontale as het aantal geanalyseerde beelden. 


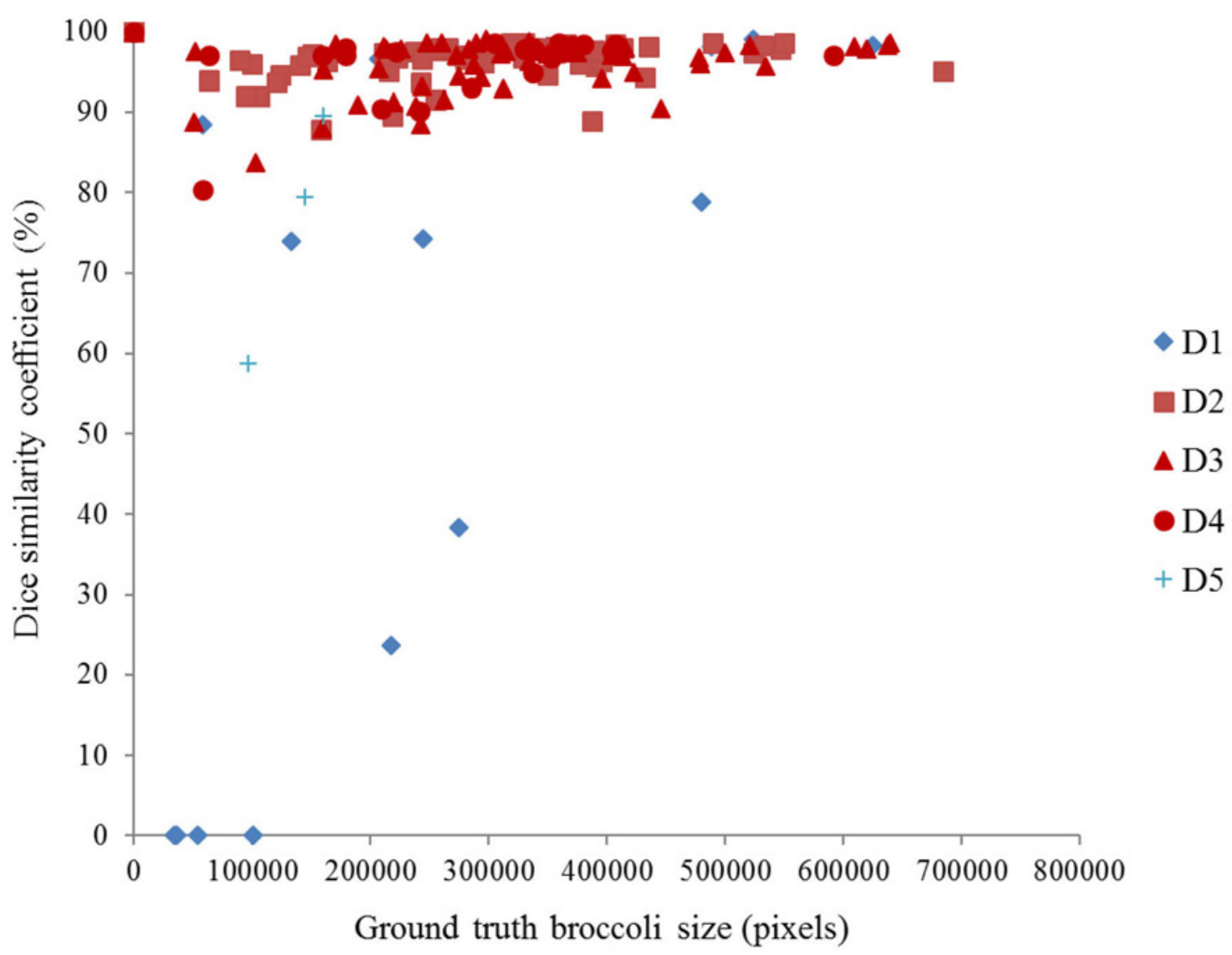

Figur 6 Grafiek van DSC uitgezet tegen de pixelgrootte van broccoli objecten van de ground truth beelden (werkelijkheid). De rode datapunten betreffen het zomergewas en de blauwe datapunten het herfstgewas.

\subsection{Object detectie van individuele broccoli kronen}

In Tabel 3 is de confusion matrix weergegeven van de computer vision object detectie ten opzichte van de werkelijkheid (ground truth). In de 200 beelden zijn 228 werkelijke broccoli kronen aangemerkt, waarvan er 208 door de computer vision software gedetecteerd zijn. De sensitiviteit, de mate van gerechtvaardigde broccoli detectie was 208/228 =91,2\%. De specificiteit, de mate van gerechtvaardigde achtergrond detectie, was $46 / 47=97,9 \%$. De precisie score van de beeld analyse was 208/209 $=99,5 \%$. Dit betekend dat als de computer vision een broccoli detecteert, de kans $99,5 \%$ is dat dit ook werkelijk een broccoli is. De waarde dat een niet broccoli object (achtergrond) als zodanig werd herkend was 46/66 $=69,7 \%$ (negative predictive value). De algemene nauwkeurigheid, weergegeven als de juistheid van de herkenning van het beeld (zowel positief als negatief) was $(208+46) / 275=92,4 \%$.

Tabel 3 Confusion matrix van broccoli kroon detectie met computer vision.

\begin{tabular}{lcccc} 
Beeld detectie beslissing & \multicolumn{3}{c}{ Ground truth } & Som \\
\cline { 2 - 4 } Broccoli & Broccoli & Achtergrond & 209 \\
\hline Achtergrond & 208 & 4 & 66 \\
\hline Som & 20 & 46 & 275 \\
\hline
\end{tabular}


Uit Tabel 4 blijkt dat de gemiddelde broccoli kroon grootte van de False Negatives kleiner was dan die van de True Positives. Uit visuele inspectie van de False Negatives beelden bleek dat de gemiste broccoli kronen in de meeste gevallen kleine (bloem)knopjes hadden of dat ze slecht belicht waren doordat ze dieper in de plant zaten.

Tabel 4 Object grootte in pixels van de true positives en false negatives.

\begin{tabular}{lcc} 
& True Positives (208) & False Negatives (20) \\
Gemiddelde grootte (pixels) & 215927.1 & 55924.8 \\
\hline St. Dev. (pixels) & 114042.1 & 67418.5
\end{tabular}

\subsection{Beeld analyse tijd}

De beeld analyse werd met een laptop uitgevoerd, welke een Intel Core i7-2030QM processor ( $2 \mathrm{GHz}$ kloktijd) bevatte. Gemiddeld kostte het 0,27 seconden $( \pm 0,04 \mathrm{~s})$ om een 5 megapixel beeld te analyseren. De software bevatte een subroutine met extra beeldanalyses wanneer het object groter was dan een bepaalde drempelwaarde. Alleen de opnames waar het object groter was dan de drempelwaarde, werden geanalyseerd door middel van kleurtransformaties (blauwe datapunten in Figuur 7). Zodoende duurde de beeld analyse langer in deze beelden, gemiddeld 0,29 s ( $\pm 0,03 \mathrm{~s})$. De beeld analyse tijd waarbij geen objecten door de drempelwaarde kwamen, was gemiddeld 0,22 s $( \pm 0,02 \mathrm{~s})$ (rode datapunten in Figuur 7).

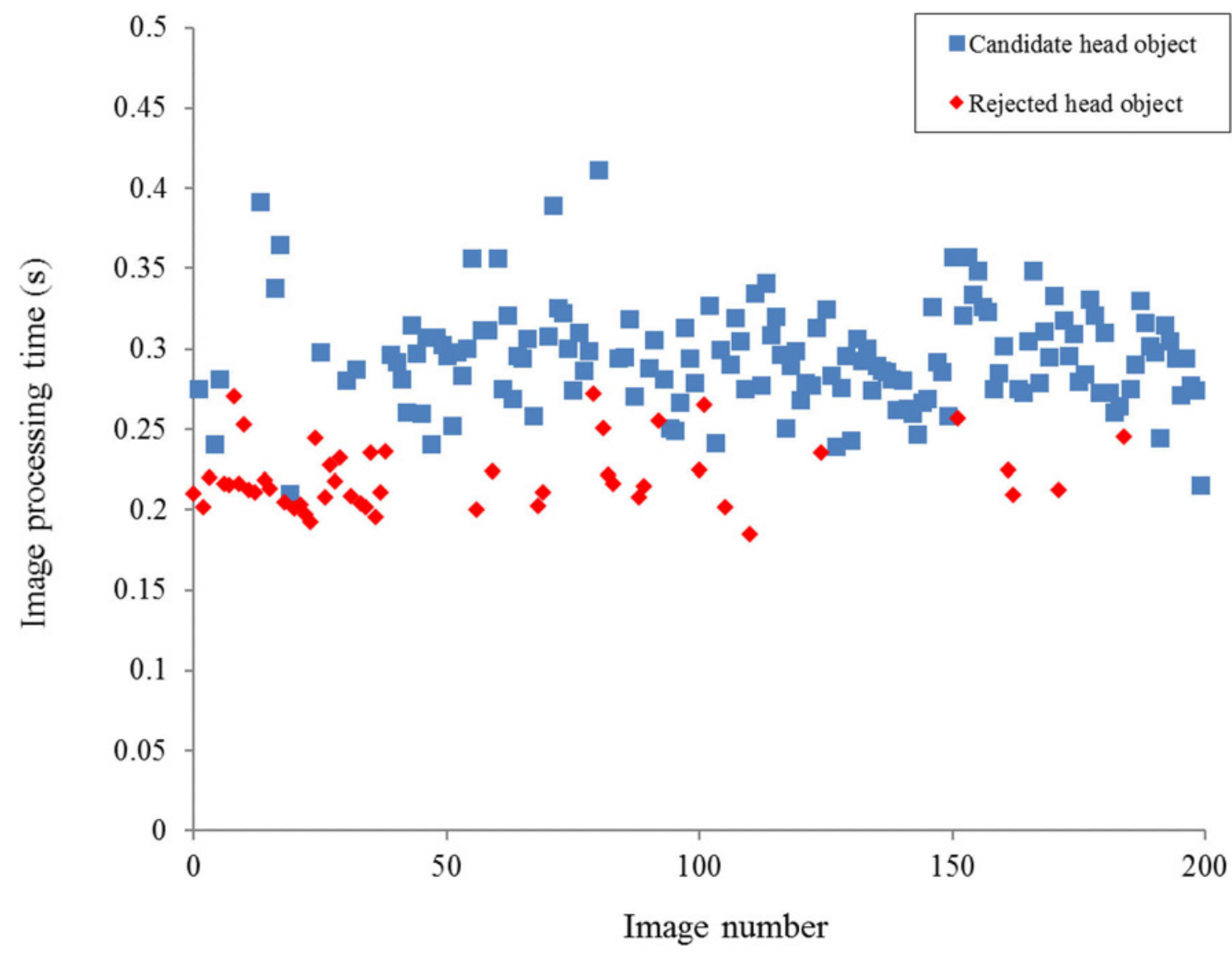

Figuur 7 Beeld analyse tijd in seconden van de 200 geselecteerde beelden. 


\section{Discussie}

De resultaten laten een hoge precisie score en Dice Similarity Coëfficiënt zien, wat veelbelovend is voor de automatische detectie van broccoli kronen in het open veld. Bij de geanalyseerde beelden ontbraken veldmetingen naar de grootte en informatie over de kwaliteit (voldoet de kroon aan de verkoopnormen). Hierdoor zijn er ook kleine en slecht belichte broccoli kronen in de dataset terecht gekomen wat invloed heeft gehad op het classificatie resultaat (de sensitiviteit score viel lager uit). De broccoli telers gaven aan dat de sensitiviteit score minder zwaar weegt dan de precisie score. Een lage precisie score en een hoog aantal False Positives zou leiden tot veel onterechte snijacties van de robotarm, wat het gewas kan beschadigen en mogelijk ook de robotarm. Daarbij werd ook aangegeven dat de selectieve machine meerdere malen door het perceel rijdt. De door de software gemiste broccoli kronen (False Negatives) kunnen doorgroeien en bij een volgende oogstmeting wel worden gedetecteerd.

De gekozen parameters en drempelwaarden in de computer vision waren handmatig geoptimaliseerd en zo gevoelig voor misclassificaties. Zodoende werden er 20 werkelijke broccoli kronen gemist door de software, resulterend in een misclassificatie ratio van $8.8 \%$ (100\%-91.2\%). Dit kan mogelijk veroorzaakt zijn door de huidige hardware setup van de acquisitiemodule, die mogelijk suboptimaal was. De beperkte scherptediepte van de camera veroorzaakte bij sommige broccoli kronen een ietwat wazig beeld, zeker wanneer deze kronen dieper in het gewas zaten of overschaduwd werden door omringende bladeren. Zodoende werden sommige kronen niet gedetecteerd door het Law's texture filter. Een verhoging in scherptediepte, door het toepassen van een lens met kleinere diafragma, verbeterd waarschijnlijk de detectie. Daarnaast zou een hogere illuminatiewaarde (door bijvoorbeeld een intensieve lichtpuls) de belichting van lager gelegen broccoli kronen kunnen verbeteren.

Door de willekeurige selectie van beelden uit de vijf datasets, kon er niets gedaan worden met de positie van de kroon in de gewasrij. De broccoli's in het veld worden gepland op vaste afstanden en deze informatie zou meegenomen kunnen worden in een probabilistisch classificatiealgoritme (bijvoorbeeld een Kalman Filter of Particle Filter). Deze zou in combinatie met een Fast-Fourier Transform (FFT) de detectie aanzienlijk kunnen verbeteren.

3D beeldinformatie kan ook extra kenmerken toevoegen voor een betere detectie. De bolvorm van een broccoli kroon kan mogelijk een ander onderscheidend kenmerk vormen en leiden tot een betere detectie van de kronen diep in de plant, waardoor het aantal False Negatives kan worden verlaagd. 


\section{$5 \quad$ Conclusie}

De resultaten van dit onderzoek tonen aan dat computer vision kan worden gebruikt om broccoli kronen te detecteren, als eerste stap in de ontwikkeling van een volledig autonome selectieve broccoli oogstrobot. De ontwikkelde vision software, gebaseerd op textuur en kleur kenmerken, bleek de beste resultaten te geven bij grote en goed belichte broccoli kronen. 20, veelal kleine en slecht belichte, broccoli kronen werden niet gedetecteerd door de computer vision. Het is de vraag of deze missers werkelijk oogstbare broccoli kronen waren, doordat een veldmeting van de werkelijke grootte niet kon worden uitgevoerd. In deze dataset ontbrak zodoende een referentie van niet-verkoopbare en verkoopbare broccoli kronen. Om deze informatie in te winnen, worden additionele sensoren en software geadviseerd, zoals 3D sensoren, lenzen met kleinere diafragma's en probabilistische classificatiealgoritmen. Deze toevoeging zal waarschijnlijk de hoeveelheid gemiste broccoli kronen doen verminderen en de computer vision aanzienlijk verbeteren. 


\section{Literatuur}

Dice, L.R. (1946). Measures of the Amount of Ecologic Association Between Species. Ecology, 20 (3), 297-302.

Everaarts, A.P. (1993). Teelt van broccoli. Teelthandleiding nr 54. PAGV. Lelystad

Grubben, G.J.H. and Denton, C.M. (2004). Plant resources of tropical Africa 2: vegetables, 139. PROTA Foundation/Backhuys Publishers/CTA, Wageningen.

Laws, K.I. (1980). Textured Image Segmentation. Ph.D. Thesis, University of Southern California.

Qui, W. and Shearer, S.A. (1992). Maturity assessment of broccoli using the discrete Fourier transform. Transactions of the ASAE. 35(6):2057-2062

Ramirez, R. (2006). Computer Vision Based Analysis of Broccoli for Application in a Selective Autonomous Harvester. Master's Thesis, Virginia Polytechnic Institute and State University.

Rother, C., Kolmogorov, V. and Blake, A. (2004). Grabcut: Interactive foreground extraction using iterated graph cuts. ACM Transactions on Graphics (TOG), 23(3), 309-314.

Schreuder, R. and Hendriks-Goossens, V.J.C. (2010). Kwantitatieve Informatie Akkerbouw en Vollegrondsgroenteteelt 2009, 169-171. PPO-AGV, Lelystad.

Soule, H.M. and Sides, S.E. (1988). Engineering aspects of the Maine broccoli industry. ASAE Paper No. 88-1577. St. Joseph, MI:ASAE.

Surendra, K.D., Klonsky, K.M. and Tumber, K.P. (2012). Sample Costs to Produce Fresh Market Broccoli. [online] UC Davis. http://coststudyfiles.ucdavis.edu/ uploads/cs_public/84/2e/842e78c33f2c-4595-ab4b-230b89b24150/broccoli_cc2012.pdf [Accessed 8 Mar. 2016].

UNECE Standard FFV-48 (2010) [online] UNECE.

http://www.unece.org/fileadmin/DAM/trade/agr/standard/fresh/FFV-

Std/English/48Broccoli_2010.pdf [Accessed 8 Mar. 2016].

Walton, L.R. and Casada, J.H. (1988). Evaluation of broccoli varieties for mechanical harvest. Applied Engineering in Agriculture, 4(1), 5-7. 
Correspondentie adres voor dit rapport: Postbus 16

6700 AA Wageningen

T 0317480700

www.wur.nl/plant-research

Rapport WPR-799
De missie van Wageningen University \& Research is 'To explore the potential of nature to improve the quality of life'. Binnen Wageningen University \& Research bundelen Wageningen University en gespecialiseerde onderzoeksinstituten van Stichting Wageningen Research hun krachten om bij te dragen aan de oplossing van belangrijke vragen in het domein van gezonde voeding en leefomgeving. Met ongeveer 30 vestigingen, 5.000 medewerkers en 10.000 studenten behoort Wageningen University \& Research wereldwijd tot de aansprekende kennisinstellingen binnen haar domein. De integrale benadering van de vraagstukken en de samenwerking tussen verschillende disciplines vormen het hart van de unieke Wageningen aanpak. 



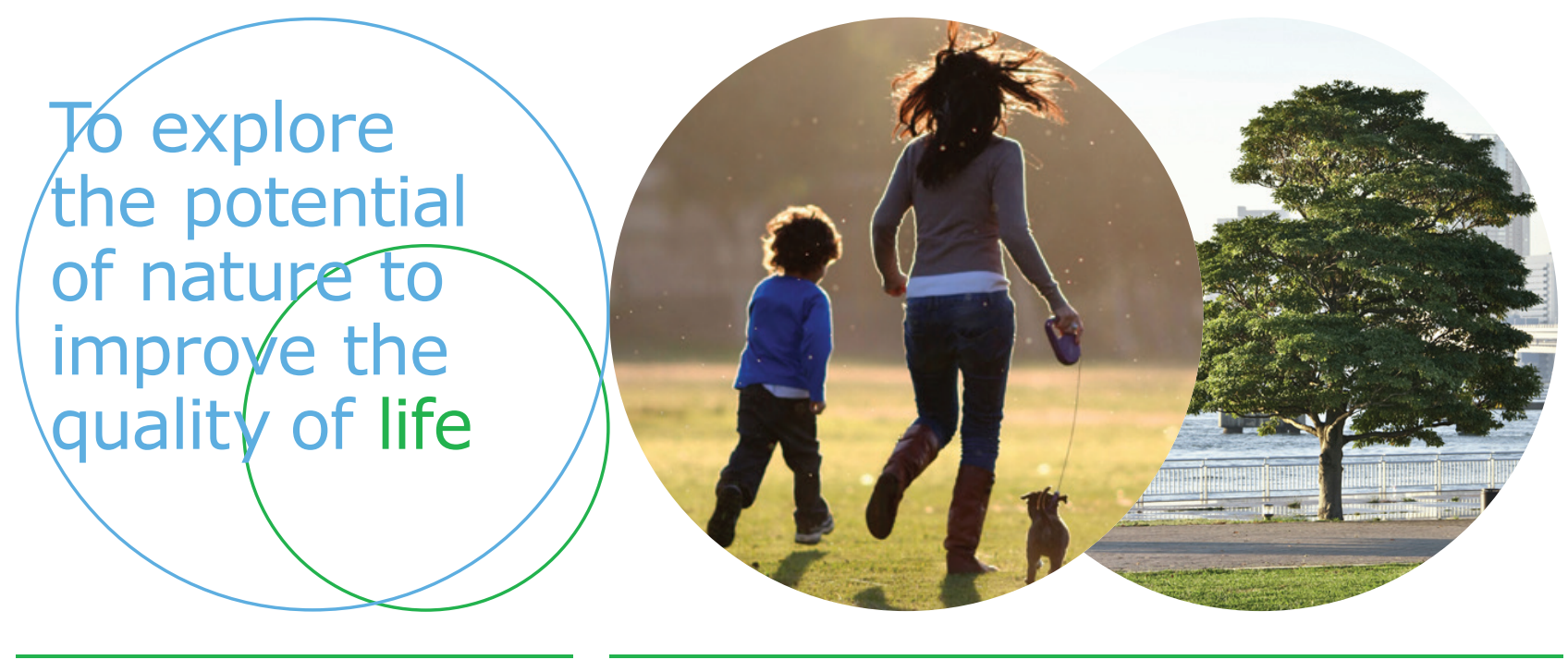

Corresponding address for this report: Postbus 16

6700 AA Wageningen

T 0317480700

www.wur.nl/plant-research

Rapport WPR-799
De missie van Wageningen University \& Research is 'To explore the potential of nature to improve the quality of life'. Binnen Wageningen University \& Research bundelen Wageningen University en gespecialiseerde onderzoeksinstituten van Stichting Wageningen Research hun krachten om bij te dragen aan de oplossing van belangrijke vragen in het domein van gezonde voeding en leefomgeving. Met ongeveer 30 vestigingen, 5.000 medewerkers en 10.000 studenten behoort Wageningen University \& Research wereldwijd tot de aansprekende kennisinstellingen binnen haar domein. De integrale benadering van de vraagstukken en de samenwerking tussen verschillende disciplines vormen het hart van de unieke Wageningen aanpak. 